\title{
LA CONTABILIDAD SOCIAL-ORIGEN Y PARADIGMAS
}

CPC Miguel Díaz Inchicaqui*

\begin{abstract}
RESUMEN
El presente artículo tiene por objetivo hacer conocer al Contador Público los orígenes evolutivos de la Contabilidad Social, presentando para ello las teorias que la sustentan, como la: Neoclásica o Marginalista, las Institucionales y las teorias Criticas, de las cuales se desprende un factor cualitativo de importancia denominada la "responsabilidad social de la empresa" aspecto que debe ser tomada en cuenta por la empresa moderna para hacer frente a los problemas sociales que se originan por su actuación en un sector económico determinado; es decir, las empresas modernas deben considerar en la información contable que expongan los efectos sociales y medioambientales de su actividad económica, conllevando con ello que el Contador Público conozca, entienda y dé la debida importancia a la Contabilidad Social. Por último al presentar un análisis de los paradigmas de la Contabilidad Social esperamos motivar a los investigadores para abordar soluciones razonables sobre esta rama de las Ciencias Contables.
\end{abstract}

\section{INTRODUCCIÓN}

La Contabilidad como ciencia de la información empresarial a lo largo de su historia ha buscado siempre satisfacer los requerimientos de sus usuarios internos $y$ externos, procesando los recursos básicos como: la materia prima, máquinas, el capital o dinero y los recursos humanos, sin tomar en cuenta que la empresa es una unidad económica de un subsistema social que está obligada además de ello en administrar con responsabilidad social dichos recursos que conllevan al cumplimiento de las aspiraciones y demandas de la colectividad. Por lo que en la actualidad es imperioso preguntarnos como contadores públicos: ¿qué responsabilidad tienen las empresas respecto a los impactos sociales derivadas de sus actividades? ¿Realizan actuaciones que mitiguen o eviten estos efectos negativos?

Es decir, debemos tomar en cuenta a la responsabilidad social como un elemento que debe ser compartido por todos los estamentos de la empresa en la medida que a cada uno les corresponda, entre los cuales es importante señalar la labor que le compete a los profesionales de la contabilidad como uno de los principales elaboradores y gestores de los sistemas de información empresarial, que estamos obligados a cubrir estos nuevos objetivos y funciones

\footnotetext{
* Profesor Asociado de la Facultad de Ciencias Contables.
} 
derivados de la ampliación de la sensibilización social con el fin de dar a conocer cómo está actuando la empresa o ente económico en relación con el entorno socioeconómico y natural.

Bajo esta sensibilidad social vigente la ciencia contable debe sufrir transformaciones como consecuencia de las nuevas exigencias informativas que le llegan tanto del exterior como internamente debido a la ampliación de las responsabilidades sociales que tienen las empresas o entidades en la actualidad. De esta manera el objetivo de rendición de cuentas a los propietarios e inversionistas se ha ampliado por las exigencias de transparencia y control de todo lo que afecta al bienestar social.

Estas exigencias modernas asociadas a la sensibilización creciente por el nivel y calidad de vida nos exige que adicionemos a nuestra información tradicional la presentación de un mayor volumen de datos de tipo social, ético, medioambiental o ecológicos, que viene a denominarse Contabilidad Social.

\section{ORIGEN DE LA CONTABILIDAD SOCLAL}

El origen evolutivo de la contabilidad social se sustenta en las siguientes teorías:

1. La teoria neoclásica o marginalista, hay dos corrientes en el estudio de la contabilidad medioambiental cuyo origen teórico puede encuadrarse en la economía neoclásica:

- Teoria del beneficio verdadero, esta teoria sostiene que la empresa en la determinación de sus resultados ignora los efectos sociales y medioambientales por lo que, la información dada a través de la contabilidad social podría medir su contribución neta a la sociedad. Para determinar esta contribución se debe considerar los efectos externos sociales y medioambientales que es originada en el proceso productivo, considerando necesario la valoración de esos efectos externos generados en la economia medioambiental. Este proceso de valorización medioambiental tiene muchas limitaciones ya que es inaceptable moralmente monetizar ciertos aspectos de la vida humana o la extinción de alguna especie, ya que existe una dificultad en elegir una tasa de descuento social, por ejemplo, para la valorización del efecto de los costos nucleares futuros; estas dificultades operativas e inconsistencias a los modelos de valorización han conducido a esta teoría a una solución práctica "calcular el costo para evitar los efectos externos sociales y medioambientales".

- La teoria de utilidad, esta teoria sostiene que las empresas deben informar a la sociedad aquellas actividades que realizan y las afecta con la finalidad que exista evidencia para que los usuarios individuales la consideren en la toma de decisiones, además de generar evidencia para que el mercado de capitales utilice esta información en la determinación de los valores adecuados que circulan en ella, es decir, la información medioambiental deberia implicar un cambio en la valorización de activos de las empresas. 
2. Teorias Institucionales, genera dentro de ella las siguientes teorías:

- Teoria del participe. Esta teoría es una extensión democrática ya que menciona que la democracia no ha de ser vasalla sólo de los propietarios del capital, promoviendo la responsabilidad social y medioambiental que tienen las empresas con la sociedad. Bajo esta teoria la contabilidad debe servir para que las empresas rindan cuentas de los mecanismos coercitivos determinados por el Estado bajo contrato social con la finalidad de informar de estos asuntos a los individuos, organizaciones y a la sociedad en su conjunto de los que depende la empresa.

- Teoría de la legitimación. La legitimidad institucional se da a través de mecanismos coercitivos y/o miméticos, ya que la mayor parte de las empresas no informan sobre los aspectos medioambientales, sin embargo, sostiene que la cantidad y calidad de la información social sea modificada como resultado de la existencia de una brecha de legitimidad.

- Teoria constructivista. La Contabilidad es un influyente mecanismo de gestión económica y social por lo que se le considera como un elemento importante para la construcción social de la realidad. Esta teoría sostiene que podría elaborarse una contabilidad no excluyente bajo mecanismos de institucionalización, ya que la contabilidad tradicional no considera al medio ambiente como parte de la información a divulgarse.
3. Teoria Critica. Esta teoria sostiene que la producción social es una confluencia de esfuerzos que hace la sociedad para llegar al fruto social; sin embargo, observa que sólo se recompensa al individuo que participa en esta producción a través de un salario dejando de lado a los otros factores que participan en esta producción social. Esta teoría analiza las clases y comportamientos del mercado, la determinación del valor de los bienes y servicios, y al Estado que como cualquier organización participa bajo sus propios intereses. Es decir, a través de estos informes contables se tiene una visión más emancipada de la motivación humana al reconocer en ella la existencia del poder y de los conflictos en la sociedad que afectan la distribución de la riqueza, y renta, destacando la importancia de los entornos históricos e institucionales de la sociedad.

\section{EL RECONOCIMIENTO DE "LA RESPONSABILIDAD SOCIAL DE LA EMPRESA"}

Existen distintas definiciones y posiciones acerca de lo que se entiende por responsabilidad social de la empresa, en consonancia con el papel otorgado a la empresa en la sociedad, ya que la empresa moderna no puede limitarse a la responsabilidad única de ofrecer bienes y servicios, sino que debe incrementar sus objetivos empresariales incorporando los que hacen referencia al entorno natural y social con el que potencialmente 
puede relacionarse cada una de ellas. Para desarrollar esta responsabilidad debe tenerse en cuenta las necesidades e intereses de los grupos sociales que puedan verse afectados por la actuación de la empresa o entidad.

Esto conlleva a manifestar que el concepto de responsabilidad social no ha sido el mismo en las distintas épocas, ya que hasta la primera mitad del siglo XX no existía como tal, posteriormente las empresas comienzan a aceptar la existencia de la responsabilidad participando en el bienestar de la sociedad a través de actividades sociales. Recién en la segunda mitad del siglo XX la sociedad toma conciencia de la capacidad del sector privado para influir y solucionar los problemas sociales, reconociéndose asimismo los daños y riesgos que el mismo ocasionaba en su entorno. Esto último originó una presión para que el gobierno interviniese imponiendo normas con el fin de la protección del interés público y los recursos naturales. En esta evolución de la responsabilidad social muchas empresas, instituciones y gobierno intentan encontrar un método de hacer frente al cambio social que se caracteriza por una mezcla de obligaciones que emanan de las normas del gobierno y la propia sensibilidad de las empresas.

Como vemos las entidades empresariales modernas tienen que ensanchar sus funciones y objetivos de negocios como consecuencia de la asunción de nuevas responsabilidades sociales, pasando de la maximización del beneficio a la incorporación de aspectos sociales y naturales en el ámbito de sus propias decisiones. Esta responsabilidad social va a ir cambiando tal como evolucionen las expectativas de actuación que se generen en el entorno empresarial de los negocios.

En el siguiente cuadro resumen, observemos objetivamente las diferentes modalidades de interpretación que se ha dado a la responsabilidad y su relación con los tipos de responsabilidad social que asume la empresa:

En conclusión, empresa, gobierno y sociedad han ido interrelacionando de tal forma que han cambiado sus papeles originales hacia actuaciones en las que las decisiones de los distintos partícipes no son independientes sino que suelen estar influenciadas, o incluso impuestas, por otros grupos sociales.

\begin{tabular}{|c|c|}
\hline Interpretaciones & Tipo de responsabilidad social \\
\hline $\begin{array}{l}\text { 1. La responsabilidad exclusivamente económica: ofrecer bienes } \\
\text { y servicios para obtener el máximo beneficio posible. }\end{array}$ & $\begin{array}{l}\text { No asumen ninguna responsabilidad } \\
\text { social. }\end{array}$ \\
\hline $\begin{array}{l}\text { 2. La responsabilidad considera aquella dimensión política de la } \\
\text { empresa en la que colabora en la búsqueda de solución de los } \\
\text { problemas como mero asesor. }\end{array}$ & \multirow{2}{*}{$\begin{array}{l}\text { La asumen voluntariamente como } \\
\text { medio de colaborar o de conseguir } \\
\text { otros objetivos principales de } \\
\text { negocios. }\end{array}$} \\
\hline $\begin{array}{l}\text { 3. La responsabilidad social con carácter instrumental es una } \\
\text { actividad para solucionar problemas de distintos grupos so- } \\
\text { ciales, pero como un medio de alcanzar resultados económicos }\end{array}$ & \\
\hline $\begin{array}{l}\text { 4. La responsabilidad social como asunción de una responsa- } \\
\text { bilidad frente a la sociedad, que supone una ampliación de los } \\
\text { objetivos empresariales a los componentes sociales. }\end{array}$ & $\begin{array}{l}\text { Las empresas la asumen dentro de } \\
\text { sus objetivos estratégicos. }\end{array}$ \\
\hline
\end{tabular}




\section{LA CONTABILIDAD SOCIAL: CONCEPTO, OBJETIVOS $Y$ CARACTERISTICAS}

Las nuevas responsabilidades sociales que aparecen para las empresas suponen el incremento de demandas informativas, tanto desde el exterior como para la gestión de la entidad. Como consecuencia las compañias han venido elaborando una serie de informaciones para cubrir esas demandas. La agrupación de todos estos datos se le ha denominado de diversas maneras como son: información social de la empresa, información o contabilidad sobre la responsabilidad social, información de base social, contabilidad social, etc. Con el objetivo de homogeneizar la nomenclatura la denominaremos Contabilidad Social o de base social, en la que se incluyen las informaciones que genera la entidad para reflejar diversos aspectos sociales sobre los que puede impactar su actividad como son cuestiones relativas a los empleados, la comunidad social, el medio ambiente y otras cuestiones éticas.

En América Latina en las décadas de los sesenta y ochenta habia una minima trascendencia de la responsabilidad social de las empresas hacia la sociedad porque sólo se dedicaban a realizar su papel principal y culturalmente atribuian el aspecto social al Estado; posteriormente, por los años noventa después de la etapa de privatización y desregulación de la economía nos incorporamos tardiamente al modelo anglosajón que hablaba de la responsabilidad social de las empresas asociada a los problemas medioambientales.
1. Conceptos. Existen diversas definiciones y conceptualizaciones para enfocar lo que se entiende por Contabilidad Social. Estas definiciones se diferencian por los temas o áreas objeto de tratamiento y por el ámbito económico en la que va a ser utilizado, como ejemplo de las diferentes definiciones que existen podemos mencionar algunas que consideramos son las más importantes:

- American Accounting Association no establece una definición propia de contabilidad social, la define utilizando el concepto genérico de la contabilidad manifestando que "La contabilidad es la técnica y/o ciencia de medición e interpretación de las actividades y fenómenos que son de naturaleza económica y social esencialmente".

- Otros como Seidler y Seidler manifiestan que la contabilidad social es la "Modificación y aplicación de las prácticas, técnicas y disciplina de la contabilidad convencional, al análisis y solución de los problemas de naturaleza social".

- Para Ramanathan es el "Proceso de selección de variables del comportamiento social de la empresa, las medidas y los procedimientos de medición, el desarrollo de información útil para la evaluación del comportamiento social y la comunicación de esa información a los grupos sociales interesados".

- Gray, Owen y Maunders consideran que la contabilidad social puede tener dos sentidos: 
la primera a través de la "Presentación de la información financiera acerca de los costos y beneficios relativos al impacto del comportamiento social de la empresa" y la segunda a través de una "Presentación periódica de un informe social de la entidad".

- Por último consideramos la definición de Mathews y Perera que supone «la ampliación de los objetivos de la contabilidad tradicional hacia nuevas áreas de información como la información sobre empleados, productos, servicios al vecindario y la prevención o reducción de la contaminación".

De todas estas definiciones descritas podemos esbozar una que reúne nuestro pensamiento manifestando que la Contabilidad Social es el: "Proceso de comunicar los efectos sociales y medio ambientales de la actividad económica de las organizaciones a determinados grupos de interés en la sociedad y a la sociedad en su conjunto. Como tal, implica extender la responsabilidad de las organizaciones (particularmente las empresas) más allá del papel tradicional de proporcionar estados financieros a los propietarios del capital o inversionistas (particularmente a los accionistas). Tal extensión se basa en que las empresas tienen responsabilidades más amplias que hacer dinero para sus accionistas".

Objetivos. De las diferentes conceptualizaciones que hemos analizado sobre la Contabilidad Social podemos distinguir diferentes objetivos, siendo las más importantes las siguientes:
Identificar y medir la contribución social neta de la empresa en la información que reporte anualmente en sus estados financieros o en informes separados que expongan de manera transparente el comportamiento social de la empresa en el denominado "balance social".

- Suministrar información para la toma de decisiones sobre políticas y prácticas sociales que adopte la empresa en el nivel estratégico de la organización.

- Contribuir a determinar si las estrategias y prácticas sociales de la empresa son consistentes con las prioridades sociales.

- Informar a la colectividad sobre la contribución social de la empresa ya sea en los campos de impacto medioambiental como en los de recursos humanos y éticos.

2. Características. Las características de la Contabilidad Social dependerán de las principales divisiones que se hagan a la misma, con la finalidad de ayudar a su estudio y desarrollo en nuestro pais, tomaremos en cuenta el análisis que realiza Mathews y Perera en su libro Accounting Theory and Development (Teoria contable y Desarrollo, en la cual presenta el siguiente cuadro:

Todas estas áreas de estudio forman parte de la Contabilidad Social según Mathews y Perera, sin embargo, también afirma que cada una de éstas ha tenido distinto grado de desarrollo por parte de la práctica y su regulación por parte del Estado siendo las aplicables al sector 


\begin{tabular}{|c|c|c|c|}
\hline DIVISION & OBJETIVO & $\begin{array}{l}\text { ÁREA BÁSICA DE } \\
\text { UTILIZACIÓN }\end{array}$ & TEMAS ASOCIADOS \\
\hline $\begin{array}{l}\text { Contabilidad de } \\
\text { la } \\
\text { responsabilidad } \\
\text { social }\end{array}$ & $\begin{array}{l}\text { Desglose de partidas } \\
\text { individuales con impacto } \\
\text { social }\end{array}$ & Sector privado & $\begin{array}{l}\text { Informes para empleados } \\
\text { Contabilidad de recursos } \\
\text { humanos } \\
\text { Democracia industrial } \\
\text { Contabilidad } \\
\text { medioambiental }\end{array}$ \\
\hline $\begin{array}{l}\text { Contabilidad del } \\
\text { impacto total }\end{array}$ & $\begin{array}{l}\text { Medición de los costes totales } \\
\text { de dirigir una organización }\end{array}$ & Sector privado & $\begin{array}{l}\text { Planificación estratégica } \\
\text { Análisis del Costo } \\
\text { beneficio }\end{array}$ \\
\hline $\begin{array}{l}\text { Contabilidad } \\
\text { socioeconómica }\end{array}$ & $\begin{array}{l}\text { Evaluación de proyectos } \\
\text { financiados por el sector } \\
\text { público }\end{array}$ & Sector público & $\begin{array}{l}\text { Análisis coste beneficio } \\
\text { - Presupuesto base cero } \\
\text { Presupuesto por } \\
\text { programas } \\
\text { Indicadores de eficiencia } \\
\text { y eficacia } \\
\text { Auditoria de eficiencia }\end{array}$ \\
\hline $\begin{array}{l}\text { Contabilidad de } \\
\text { los indicadores } \\
\text { sociales }\end{array}$ & $\begin{array}{c}\text { Cuantificación no financiera a } \\
\text { largo plazo de las estadísticas } \\
\text { sociales }\end{array}$ & Sector püblico & $\begin{array}{l}\text { Cuentas nacionales } \\
\text { - Estadísticas nacionales }\end{array}$ \\
\hline $\begin{array}{l}\text { Contabilidad } \\
\text { societal }\end{array}$ & $\begin{array}{l}\text { Intentos para representar la } \\
\text { contabilidad en términos } \\
\text { globales }\end{array}$ & $\begin{array}{l}\text { Sector püblico y } \\
\text { privado } \\
\text { conjuntamente }\end{array}$ & $\begin{array}{l}\text { Teoría de sistemas } \\
\text { Tendencias } \\
\text { megacontables }\end{array}$ \\
\hline
\end{tabular}

público las que han tenido mayor =rado de normalización, mientras que las del sector privado han seguido una evolución más anárquica.

Para nuestro caso de estudio la onmera división expuesta es la que se acerca a los objetivos de la Jontabilidad Social que hemos Jefinido, ya que en ella se realiza el análisis del desglose de partidas tividuales de los estados financieros xn impacto social, conllevándonos a aregrarnos con la responsabilidad ミ- cial de las empresas hacia la sociedad.

\section{IT. TEORÍAS DE LA CONTABILIDAD SOCIAL}

Las teorías de la contabilidad acial son las siguientes:
1) Paradigma funcionalista 0 de mercado. Este paradigma incorpora todas las teorias basadas en la teoría económica neoclásica y la teoría clásica de gestión. Los argumentos en los que se apoya para explicar la presentación de información son aquellos relacionados con el mercado. Algunas de las ideas principales que sostienen son las siguientes:

- El objetivo de la información de tipo social es ofrecer datos útiles a los accionistas y los mercados financieros pues dicha información puede influir en la valoración de las acciones. El usuario básico de la misma es, por lo tanto, el inversor.

- Los defensores de estas posiciones consideran que no debe imponerse ningún requerimiento relativo a 
la responsabilidad social a las entidades, ya que es considerado como una aplicación incorrecta de los fondos de los accionistas.

- La maximización de la satisfacción social se logra a través del libre mercado.

En resumen, éstos son los posicionamientos tradicionales en los que el funcionamiento del mercado es el que explica todas las actuaciones relativas a la elaboración y presentación de diversos tipos de información de los cuales las de carácter social ocupan un puesto cada vez más relevante. Por tanto, este paradigma se apoya en justificaciones puramente económicas.

\section{2) Paradigma interpretativo o} social. El paradigma interpretativo se basa en argumentos sociales que consideran la existencia de un mundo social con una pluralidad de agentes usuarios de la información social generada por las entidades económicas. La información de base social ya no va dirigida principalmente al inversor, sino que también interesa a los empleados, clientes, público en general, administraciones $y$ organismos públicos, ONGs, etc. Existe una multiplicidad de usuarios.

La respuesta de los mercados de capitales ante la contabilidad social no tiene tanta relevancia para los nuevos grupos de usuarios, sino que es preciso abordar un debate moral relativo a la actuación de las empresas en la sociedad en la que operan.

Por lo tanto, estos argumentos se utilizan cuando la información de tipo social se presenta para establecer la naturaleza moral de la empresa con el fin de satisfacer el contrato social de la misma y para legitimar y justificar las actividades de estas entidades ante la sociedad en general.

En consecuencia, estos argumentos se traducen en diversos enfoques que son considerados de carácter moderado.

Los principales enfoques $y$ características existentes son:

Estos enfoques se consideran de carácter moderado porque el estado actual no es rechazado por completo (argumentos radicales), ni aceptado

\begin{tabular}{|c|l|}
\hline Teorias & \multicolumn{1}{|c|}{ Característica básica } \\
\hline Contrato social & $\begin{array}{l}\text { Las entidades económicas tienen un contrato implícito con la sociedad por el que } \\
\text { tienen el soporte legal y la autorización para poseer y utilizar recursos naturales y } \\
\text { contratar empleados. A cambio ofrecen productos, servicios y residuos al entorno, } \\
\text { con lo que la sociedad espera verse correspondida. En este sentido la presentación de } \\
\text { información social constituye la forma de explicar la utilización de todos esos } \\
\text { recursos y los resultados obtenidos. }\end{array}$ \\
\hline $\begin{array}{c}\text { Legitimidad } \\
\text { organizacional }\end{array}$ & $\begin{array}{l}\text { La teoría de la legitimidad explica la presentación de información de base social con } \\
\text { el objetivo de conseguir ser aceptados por la sociedad corno fin último. Lo importante } \\
\text { es conseguir la legitimación aún a costa de informaciones sesgadas. }\end{array}$ \\
\hline $\begin{array}{c}\text { Teoria del } \\
\text { partícipe o } \\
\text { Stakeholder }\end{array}$ & $\begin{array}{l}\text { Según esta teoría la información social es presentada por las entidades porque existe } \\
\text { un numeroso grupo de agentes sociales interesados en la misma y en el } \\
\text { funcionamiento de la entidad, y sin cuyo apoyo, explícito o implícito, peligraría la } \\
\text { propia existencia de la compañia. }\end{array}$ \\
\hline
\end{tabular}


en su totalidad (argumentos de mercado).

3) Paradigma Radical. Consiste en líneas de pensamiento con un planteamiento crítico sobre la situación existente. Está basado en los argumentos de los "teóricos críticos" que creen en un modelo de sociedad alternativo al actual, asi como un papel distinto para la contabilidad. Una de las teorias dominantes es la Economía Politica que rechaza las soluciones de mercado y considera que la estructura de la sociedad es la que determina todo lo que acontece en la misma. Según Mathews las características básicas que se desprenden de los estudios realizados con este enfoque son:

El mercado debe ser abolido o debe perder su supremacía como medio de asignación de recursos.

- Las empresas están organizadas y operan para explotar las relaciones de poder.

- Tal como está organizada la profesión contable está dedicada a mantener el status quo uniéndose a una de las partes del conflicto social (el capital), y excluyéndose de la otra parte (el trabajador).

- La profesión contable mistifica los procesos para ejercer el poder basándose en los valores de la economia marginal.

- Los contables ignoran el alcance para el que la disciplina ha sido $y$ está siendo construida dentro de la sociedad.

La contabilidad como disciplina debe cambiar para rendir cuentas de las relaciones sociales de una forma más amplia a la actual.

- Los contables, auditores, profesores de contabilidad y estudiantes deben darse cuenta de que tienen la oportunidad de tomar parte en el conflicto social a través de sus relaciones sociales.

- La contabilidad social es deficiente tal como es presentada por la mayor parte de la literatura, ya que únicamente considera la presentación de informaciones adicionales y no considera la posibilidad de cambios en la propiedad de los recursos de capital. Además regula el mecanismo del mercado en lugar de eliminarlo de forma completa.

Por 10 tanto, los autores radicales consideran que la contabilidad debe cambiar de una forma drástica sus planteamientos, incorporando nuevos puntos de vista en sus informaciones.

\section{PRINCIPALES RAMAS DE LA CONTABILIDAD SOCIAL}

1. La Contabilidad Medioambiental. Una de las ramificaciones de la Contabilidad Social de mayor relevancia es, sin duda, la Contabilidad Medioambiental ya que el creciente deterioro del medio ambiente, ocasionado por la actividad humana, está provocado fundamentalmente por las actividades empresariales de industrias correspondientes a sectores altamente contaminantes. Esto 
efectos contaminantes han generado una demanda por parte de la sociedad para que las empresas incorporen en su gestión el objetivo de preservación del entorno social y ambiental en el que operan. Ello hace preciso que las entidades integren la variable medio ambiente en su gestión a través del establecimiento de sistemas de gestión medioambiental y el establecimiento de políticas medioambientales.

Derivado de estos sistemas y politicas medioambientales surge la necesidad de establecer también sistemas de información medioambiental, tanto para la colaboración con la gestión interna de la compañia como para satisfacer las demandas informativas de agentes sociales externos. Todas estas informaciones y técnicas conformarian la Contabilidad Medioambiental como una subdivisión de la contabilidad convencional pero aplicada a los aspectos relacionados con el entorno natural.

2. La Contabilidad de los Recursos Humanos. La Contabilidad de los Recursos Humanos supone la incorporación en la información presentada por la contabilidad de uno de los componentes fundamentales de la organización: el Capital Humano el cual es estudiado y analizado dentro de la contabilización del capital intelectual.

La American Accounting Association la define como el proceso de identificación y medición de datos sobre los recursos humanos, así como la comuni- cación de esta información a las partes interesadas. El propósito de la misma es, por lo tanto, la valoración del capital humano de la empresa y la elaboración y presentación de información relativa al mismo. Esta rama de la contabilidad resurge en la actualidad debido a las nuevas exigencias planteadas por la responsabilidad social de las empresas y que, al igual que la contabilidad medioambiental se plantea incorporarla tanto por su utilidad en el ámbito interno o de gestión como en el externo.

En el ámbito externo la presentación de información está basada en su utilidad para la toma de decisiones por parte de los posibles usuarios. La demanda interna está basada en el objetivo de adoptar decisiones relativas al personal por parte de la gerencia. La ubicación de este tipo de información es otro aspecto en el que no existe consenso; sin embargo, algunos autores proponen el balance mientras otros proponen ubicarla junto al resto de datos sociales. En nuestra posición sugerimos se exponga en un apartado específico en las notas de los estados financieros y la memoria para este fin, además de presentarla como información adicional y voluntaria.

Se han propuesto distintas técnicas de valoración del capital humano como son las siguientes: El Valor del costo histórico, el Costo de oportunidad, el Costo de compensación, el Costo de reposición, Descuento de salarios futuros, el Valor económico, etc. Todas estas 
técnicas de valoración monetarias lógicamente deben basarse en el número de empleados de cada categoria existentes en la empresa. Sin embargo, es importante incorporar también a las técnicas de valoración no monetaria ya que a través de ellas se recogen informaciones relativas a determinadas cualidades del capital humano.

3. La información de carácter ético. Esta información se ocupa de los valores éticos de la empresa, en la que se incorporan datos relativos a las actuaciones de la empresa relacionadas con la protección del consumidor y de la comunidad, o de prestación de ayudas o servicios a la sociedad sin ánimo de lucro.

Los principales aspectos que se incluyen en este tipo de información son, entre otros:

- Políticas y relaciones con los clientes

- Actividades y donativos de carácter político

- Políticas, acciones y medición de actividades dirigidas a ofrecer igualdad de oportunidades entre colectivos diferenciados tradicionalmente por sexo, raza, procedencia, edad, etc.

- Actividades y Políticas relacionadas con el bienestar de la comunidad

- Publicidad y esponsorización

- Políticas y descripciones de comprobación de la seguridad de los productos y procesos productivos

- Descripción de prácticas éticas y prácticas externas no éticas

- Actividades y donativos de caridad
- Concesión de premios y becas, etc.

La regulación respecto a la publicación de este tipo de información ha sido escasa aqui en el Perú; esperamos que a partir de este artículo se le dé la importancia debida.

\section{CONCLUSIONES}

a. La Contabilidad Social se deriva de la creciente responsabilidad social que deben asumir los entes económicos surgiendo de esta manera la necesidad de elaborar y presentar información sobre las actividades relacionadas con esa responsabilidad; dentro de ella se deben incorporar distintos aspectos sociales, tales como, los de recursos humanos, del medio ambiente y de carácter ético.

b. Las distintas teorias justificativas de la Contabilidad Social, tales como teorias de mercado, sociales $y$ radicales, han evolucionado su crecimiento y necesidad de información ya sea a nivel de empresa o a nivel de los diferentes sectores socioeconómicos. Las teorias sociales o paradigma interpretativo parecen ser la tendencia actual.

c. Las entidades deben desarrollar sistemas de información que incorporen aspectos sociales de una manera más clara y estructurada de manera que justifiquen sus actuaciones (o su ausencia de actuación) en determinados campos sociales. Esta información debe servir para la adopción de decisiones tanto a nivel externo como interno de la empresa. 


\section{BIBLIOGRAFÍA}

1. Mathews, M. R. (1993) Socially Responsible Accounting, Chapman and Hall, London.

2. Mathews, M. R. y Perera, M.H. (1991) Accounting Theory and Development, Chapman and Hall, London.

3. Moneva, J. M. y Llena, F. (1996) "Análisis de la información sobre responsabilidad social en las empresas industriales que cotizan en bolsa", en Revista Española de Financiación y Contabilidad, $\mathrm{N}^{\circ} 87$, pp. 361-401.

4. Arizkuren, A. (1995) "Una aproximación al ambiguo concepto de responsabilidad social de la empresa", Estudios Empresariales, $\mathrm{N}^{\circ} 89$.

5. García Echevarría, S. (1982): Responsabilidad social y balance social de la empresa. Fundación Mapfre, Madrid. 